\title{
Ameliyathane dışı anestezi deneyimlerimiz
}

\author{
Hacer Şebnem Türk', Ferda Aybey², Oya Ünsal', Mehmet Eren Açık², Naim Ediz', Sibel Oba'
}

ÖZET:

Ameliyathane dışı anestezi deneyimlerimiz

Giriş ve Amaç: Teknolojik gelişmeler sayesinde, hastalara tanı ve tedavi amacıyla ameliyathane dışı ortamlarda invaziv ve non-invaziv uygulamalara başlanmıştır. Bu durum ameliyathane dışı anestezi (ADA) ekiplerinin kurulmasına neden olmuştur. Biz, bu çalışmada, ADA ekibimizin deneyimlerini sunmayı amaçladık.

Gereç ve Yöntem: Ekim 2010-Nisan 2012 tarihleri arasındaki ADA uygulamalarımızı retrospektif inceledik. ADA uyguladığımız 3583 olgunun cinsiyeti, yaşı, ASA'sı, yapılan girişimleri, uygulanan anestezi ilaçları ve komplikasyonları kaydedildi.

Bulgular: Olguların cinsiyet dağılımı E/K 1671/1912, yaş ortalamaları 48.52+28.4, yaş dağılımı 20 günlük - 91 yaş arasındaydı. ASA sınıflaması ASA I 1958, ASA II 1296, ASA III 318, ASA IV 11 şeklindeydi. 1837 olguya kolonoskopi, 536 olguya gastroskopi, 131 olguya ERCP uygulandı.

811 olguya MR, 62 olguya BT çekimi yapıldı. 234 seans EKT uygulaması, 106 seans RT uygulaması yapııdı. Anjiografi ünitesinde 40 olguya anevrizma embolizasyonu uygulandı. Anjiografi ünitesinde 9 olguya venöz sampling, 43 olguya karotis stent uygulaması yapıldı. Ayrıca 63 olguya girişimsel radyolojide farklı uygulamalar yapıldı.

Olguların 1960'ında propofol+alfentanil,740'ınde propofol, 544'ünde propofol+fentanil, 115'inde ketofol, 65'inde midozolam+ketamin, 83'ünde dexmetedomidin sedasyonu uygulandı. 234 EKT seansının 90'ında etomidate+süksinilkolin, 144'ünde propofol+süksinilkolin uygulandı. 40 embolizasyon olgusuna genel anestezi verildi.

Geçirilmiş serebrovasküler hastalık, hipertansiyon öyküsü olan olguda kolonoskopi işlemi esnasında intrakraniyal kanama gelişmesi dışında majör bir komplikasyonla karşılaşılmadı. 12 olguda solunum depresyonu, 41 olguda bradikardi, 144 olguda desatürasyon, 19 olguda derlenme süresinin uzaması, 8 olguda kusma gibi minör komplikasyonlarla karşılașıldı.

Sonuç: ADA uygulamaları her alanda ve her yaş grubunda sıklıkla kullanılan bir yöntemdir. Ameliyathaneden uzak olma, yetersiz donanım ve monitör, çalışma alanındaki hareket kısıtııı̆ı ADA uygulamalarını zorlayıcı kılmakta, beceri ve deneyim gerektirmektedir. Uygun donanım, ilaçlar ve yeterli koşullarda deneyimli bir anestezist ADA uygulamalarındaki başarının sırrıdır.

Ameliyathane dışı anestezi uygulamaları hasta güvenliğini ve memnuniyetini artırıp, huzursuzluk ve ağrıyı azaltmakta, hekim konforunu arttırmaktadır.

Anahtar kelimeler: Ameliyathane dışı anestezi, sedasyon, komplikasyon

ABSTRACT:

Anesthesia experiences outside of the operating room

Introduction And Aim: Thanks to technological developments, invasive and non-invasive diagnostic and therapeutic procedures have been done at the outside of the operating room. In this manner, to provide anesthesia at the outside of the operating room, anesthesia teams have been found. In this study, we aimed to report our anesthesia teams' experiences.

Materials And Methods: We reviewed the procedures that was experienced at outside the operating room from October 2010 to April 2012 retrospectively. 3583 Patients who required anesthesia at the outside of the operating room included the study, and their sexes, ages, ASA status, procedures, and anesthesia complications were recorded.

Results: Patients' sex ratio male/female 1671/1912; ranged in age from 20 day to 91 years; with the mean age 48,52 28,4 . ASA status were, ASA I 1958, ASA II 1296, ASA III 318, ASA IV 11.

Anesthesia procedures were for 1837 colonoscopy, 536 gastroscopy, 131 ERCP endoscopic retrograde cholangiopancreatography, $811 \mathrm{MRI}$ magnetic resonance imaging, $62 \mathrm{CTI}$ computerized tomography imaging, 234 ECT electroconvulsive therapy, 106 RT radiotherapy, 40 angiographic aneurysm embolization, 9 angiographic venous sampling, 43 carotis stent, and 63 other radiologic interventions.

For sedation; 1960 Patient received propofol + alfentanil, 740 only propofol, 544 propofol + fentanyl, 115 ketofol, 65 midazolam+ketamin 83 dexmedetomidine. For electroconvulsive therapies, 90 patient received etomidate + succinyl choline, 144 propofol + succinyl choline. 40 patient received general anesthesia for embolisation procedures.

There are no major complication occured except one patient experienced intracranial hemorrhage during colonoscopy. In minor complications; 12 patient experienced respiratory depression, 41 bradycardia, 144 oxygen desaturaion, 191 prolonged recovery from anesthesia, 8 vomiting.

Conclusion: Anesthesia procedures at the outside of the operating room are frequently used in all medical interventions and at all ages. Remote locations from operating room, inadequate equipment and monitors, not enough space in the working environment, providing anesthesia outside the operating room is challenging and requires expertise and skill. The secret of success in anesthesia in remote locations is the skilled anesthesiologist with the appropriate equipment and drugs, along with adequate backup facilities. Anesthesia procedures at the outside of the operating room are guarding the patients safety and welfare, minimising physical discomfort and pain, providing physicians' comfort.

Key words: Anesthesia procedures outside of the operating room, sedation, complication

Ş.E.E.A.H. Tıp Bülteni 2013;47(1):5-10
'Uzman Doktor, Şişli Etfal Eğitim ve Araştırma Hastanesi Anesteziyoloji ve Reanimasyon Kliniği, İstanbul-Türkiye

${ }^{2}$ Asistan Doktor, Şişli Etfal Eğitim ve Araştırma Hastanesi Anesteziyoloji ve Reanimasyon Kliniği, İstanbul-Türkiye

Yazışma Adresi / Address reprint requests to: Uzman Doktor Hacer Şebnem Türk, Şişli Etfal Eğitim ve Araştırma Hastanesi Anesteziyoloji ve Reanimasyon Kliniği, İstanbul-Türkiye

Telefon / Phone: +90-532-443-2544

E-posta / E-mail:

hacersebnem@yahoo.com.tr

Geliş tarihi / Date of receipt: 15 Ağustos 2012 / August 15, 2012

Kabul tarihi / Date of acceptance: 17 Ağustos 2012 / August 17, 2012 


\section{GíRiş}

Günümüzde, teknolojik ve farmakolojik gelişmeler sayesinde, hastalara tanı ve tedavisi amacıyla invaziv olmayan girişimler ve invaziv girişimler ameliyathane dışı ortamlarda uygulanmaya başlanmıştır. Bu durum potansiyel komplikasyonları ve uygulama alanlarına ait zorlukları da beraberinde getirmektedir. Sağlık harcamalarını azaltmak amacıyla invaziv olmayan cerrahi seçeneklerin tercih ediliyor olması anestezistleri hasta güvenliğini sağlamaları için ameliyathane dışına çekmektedir. Bu girişimleri, ameliyathane dışı uygulama yerlerinde, hasta ve personel güvenliğini göz ardı etmeden gerçekleştirmek için uygun ve yeterli monitorizasyon yapılmalı, bunun için ekipman konusunda temel standartları sağlamak amacıyla çaba harcanmalıdır (1).

Hastanın ve yapılacak işlemin özelliklerine göre anestezi uygulamaları; monitörize hasta bakımı temelinde sedasyon/analjezi ya da genel anestezi şeklinde sınıflandırılabilir. Sedasyon/analjezi teknikleri ile hastanın anksiyetesi, huzursuzluğu ve ağrısı azaltılablilir. Ayrıca, hareketsizlik gerektiren girişimlerde, küçük çocuk ve kooperasyon kurulamayan erişkin hastaların hareket etmesi önlenerek girişimin başarısı artırılabilir (2).

Bu çalışmamızda Ekim 2010- Nisan 2012 tarihleri arasında hastanemizde kurduğumuz ameliyathane dışı anestezi (ADA) ekibi tarafından, ADA uygulanan 3583 olgunun demografik verilerini, uygulama alanlarını, anestezi teknikleri ve komplikasyonları sunmayı amaçladık.

\section{GEREÇ VE YÖNTEM}

Çalışmamız için, Şişli Etfal Eğitim ve Araştırma Hastanesi Etik kurulundan onay alındıktan sonra, Ekim 2010- Nisan 2012 tarihleri arasında tanı ve tedavi amacıyla ameliyathane dışında anestezi uygulaması yapılan 3583 olgunun anestezi kayıtları incelendi. Olguların demografik verileri, uygulama alanları, uygulanan anestezi yöntemleri ve gelişen komplikasyonlar kaydedildi.

Hastanemizde ADA uygulamaları tanı ve tedavi amaçlı olarak cerrahi, erişkin ve çocuk gastroenteroloji endoskopi ünitelerinde, psikiyatri elektro kon- vülzif terapi (EKT) ünitesinde, bilgisayarlı tomografi (BT), manyetik rezonans görüntüleme (MRG) ve radyo terapi (RT) ünitelerinde çocuk hasta uygulamalarında, anjiografi ünitesinde yapılmaktadır. ADA ekibimiz, bir anestezi uzmanı, bir anestezi asistanı ve bir anestezi teknisyeninden oluşmaktadır. ADA ekibimiz uygulamalarına Ekim 2010 tarihinde başlamıştır.

ADA ekipmanımız, Türk Anesteziyoloji ve Reanimasyon Derneği'nin 2005 yılında yayınladığı ameliyathane dışı anestezi uygulamaları klavuzuna göre belirlenmiştir. Tüm ünitelerde; oksijen kaynağı, kalp atım hızı, tansiyon arteriyel ve oksijen satürasyon ölçümü yapabilen monitör, aspiratör, laringoskop, acil resüsitasyon malzemesi içeren acil çantası veya dolabı, defibrilatör yer almaktadır. Ayrıca genel anestezi uygulamalarının da yapıldığı EKT, anjiografi ve MRG ünitelerinde anestezi cihazı da bulunmaktadır. MRG ünitesinde kullanılan monitör, anestezi cihazı, aspiratör ve laringoskop MR uyumludur. MRG ve RT ünitelerinde hasta başı monitör dışında, hastanın dışarıdan takibine olanak sağlayan merkezi monitörde yer almaktadır. ADA bitiminde hastalar bulunduklar ünitede ki derlenme bölümünde ya da ameliyathanenin uyanma ünitesinde takip edilerek, derlenme sonrasında taburcu edilmektedirler.

Bu koşullar altında ADA uygulanan olguların Ekim 2010 - Nisan 2012 tarihleri arasındaki anestezi kayıtları geriye dönük incelenerek yaş, cinsiyet gibi demografik verileri, ASA'ları, uygulama alanları, kulIanılan anestezi teknikleri ve ilaçları, bradikardi, taşikardi, hipotansiyon, hipertansiyon desatürasyon, solunum depresyonu, bulantı, kusma, alerjik reaksiyon, uzamış sedasyon gibi komplikasyonlar kaydedildi. Kalp hızı normalin \%25 altında ise bradikardi olarak değerlendirildi ve atropin ile tedavi edildi. Periferik oksijen satürasyonu \%90'ın altı desatürasyon olarak kabul edildi ve başın pozisyonun değiştirilmesi, air-way uygulaması ve/veya maske ile oksijen verilerek tedavi edildi. Sedasyon verilen hastaların 30 dakika sonunda ramsey sedasyon skorunun 2'ye gelmemiş olması uzamış sedasyon olarak değerlendirildi.

İstatistiksel değerlendirmede SPSS 15.0 programı kullanılmıştır. 


\section{BULGULAR}

Şişli Etfal Eğitim ve Araştırma Hastanesi'nde Ekim 2010-Nisan 2012 tarihleri arasında ADA uygulanan 3583 olgunun, cinsiyet dağılımı E/K 1671/1912, yaş ortalamaları 48.52 \pm 28.4 yıl, yaş dağılımı 20 günlük 91 yaş arasındaydı. ASA sınıflaması ASA I 1958, ASA II 1296, ASA III 318, ASA IV 11 şeklindeydi (Tablo 1).

Tablo 1: Demografik Veriler ve ASA Dağılımları

\begin{tabular}{ll}
\hline Yaş Ortalaması (Yıl) & $\mathbf{4 8 . 5 2 \pm 2 8 . 4}$ \\
\hline Cinsiyet (E/K) & $1671 / 1912$ \\
ASA & Sayılar \\
I & 1958 \\
II & 1292 \\
III & 318 \\
IV & 11
\end{tabular}

ADA uygulama alanlarının dağılımları Grafik 1'de verilmiştir.

\section{$\square$ Kolonoskopi $\square$ Gastroskopi $\square$ ERCP $\square$ MRG BT 口EKT $\square$ RT $\square$ Annjioü. घGirişimsel Rad.}

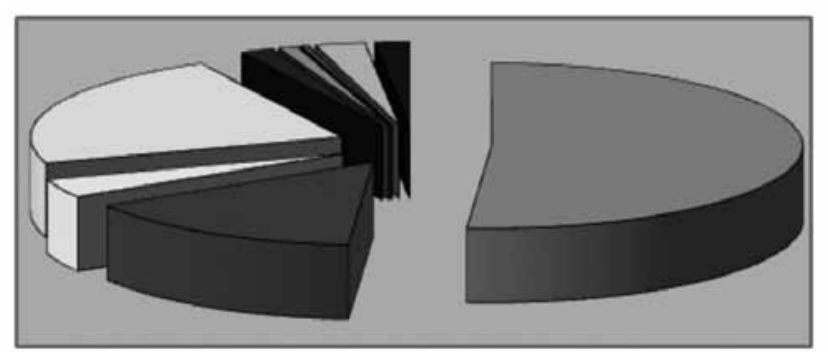

Grafik 1: ADA Uygulama Alanlarının Dağılımı

\section{Propofol+alfentanil $\square$ Propofol+fentanil $\square$ Ketofol $\square$ Propofol $\square$ Deksmedetomidin Midozolam+Ketamin}

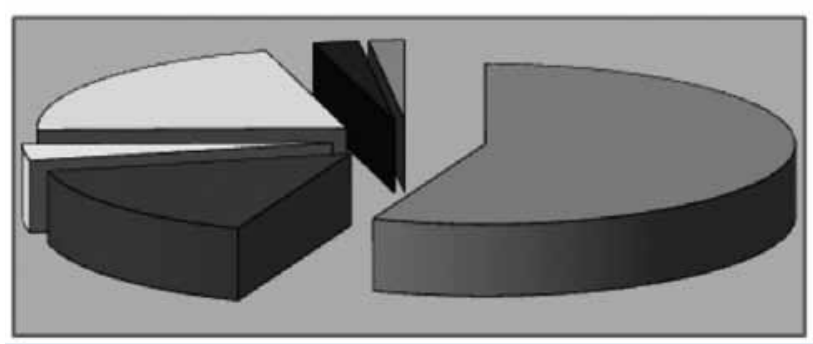

Grafik 2: Kullanılan Sedatif Ajan Dağılımı
1837 olguya kolonoskopi uygulandı. Bunların 33'üne kolon stenti yerleştirildi. Kolonoskopi uygulanan 17 olgu pediatrik yaş grubundaydı. 536 olguya gastroskopi uygulandı. Bunların 12'sine özofagus dilatasyonu, 23'üne Perkütan Endoskopik Gastrostomi (PEG )açılması, 42'sine intragastrik balon uygulaması yapıldı.131 olguya Endoskopik Retrograt Kolanjiopankreatografi (ERCP) uygulandı. Kolonoskopi, gastroskopi ve ERCP uygulanan olguların yaş ortalaması $56.01 \pm 18.3^{\prime}$ tü.

811 olguya MR, 62 olguya BT çekimi yapıldı. Bu olguların yaş ortalaması $3.53 \pm 3.6^{\prime}$ tü. 36 olguya 234 seans EKT uygulaması, 15 olguya 106 seans RT uygulaması yapıldı.

Anjiografi ünitesinde 40 olguya anevrizma embolizasyonu uygulandı. E/K 16/24, yaş ortalaması $55.6 \pm 15.4$ 'tü. Bu olgulara genel anestezi uygulanıp, orotrakeal entübe edildi. Anjiografi ünitesinde 9 olguya venöz sampling, 43 olguya karotis stent uygulaması yapıldı. Ayrıca 21 nefrostomi açılması, 14 US eşliğinde abse drenajı, 6 PTK, 329 US eşliğinde biopsi, 6 kalıcı dializ kateteri takılması, 3 double J takılması gibi 63 girişimsel radyolojik işlem yapıldı.

Olguların 1960'ında propofol+alfentanil, 740'ınde propofol, 544'ünde propofol + fentanil, $115^{\prime}$ inde ketofol, 65'inde midozolam+ketamin, 83'ünde dexmetedomidin sedasyonu uygulandı. 234 EKT seansının 90'ında etomidate + süksinilkolin, $144^{\prime}$ ünde propofol + süksinilkolin uygulandı. 40 embolizasyon olgusuna genel anestezi verildi (Grafik 2).

Endoskopik girişimlerde 1890 olguda propofol + alfentanil, 499 olguda propofol + fentanil, 115 olguda ketofol tercih edildi. MRG ve BT'de 725 olguya propofol, 83 olguya deksmetedomidin, 65 olguya midozolam + ketamin uygulandı. 15 olguya uygulanan 106 Seans RT'nin tümünde propofol kullanıldı.

Geçirilmiş serebrovasküler hastalık, hipertansiyon öyküsü olan olguda kolonoskopi işlemi esnasında intrakraniyal kanama gelişmesi dışında majör bir komplikasyonla karşılaşılmadı.12 olguda solunum depresyonu, 41 olguda bradikardi, 144 olguda desatürasyon, 19 olguda derlenme süresinin uzaması, 8 olguda kusma gibi minör komplikasyonlarla karşılaşıldı. 20 desatürasyon ve 3 solunum depresyonu MRG ve BT çekilen pediatrik olgularda görülmüştür. 
Desatürasyon gelişen olgularda çene asma ve oksijen verilmesi ile saturasyon değerleri düzeldi. Maske ile ventilasyon ya da entübasyon ihtiyacı doğmadı. Bradikardi gelişen olgularda atropin uygulandı.

\section{TARTIŞMA}

Son yıllarda, teknolojinin ve cerrahinin gelişmesi ile ameliyathane dışındaki teşhis ve tedaviye yönelik günübirlik işlemler artmıştır. Bu durum anestezi servislerinin ameliyathane dışı anestezi ekiplerini kurmasına yol açmıştır. Ameliyathaneden uzak olma, tam donanımlı olmayan bir ortamda anestezi verilmesi, hastalardan uzak çalışma alanları vb. riskler ameliyathane dışı anestezi uygulamalarını özellikli kılmaktadır $(2,3)$.

2005 yılında Türk Anesteziyoloji ve Reanimasyon Derneği'nin yayınladığı ameliyathane dışı anestezi uygulamaları klavuzu ve Amerikan Anestezi Derneği'nin klavuzu ADA uygulamaları konusunda standartların oluşması konusunda yol gösterici olmuştur $(2,4)$. Uygulama yapılacak ünitelerde bulundurulması gereken ilaç ve ekipmanlar, ortam koşulları belirtilmiştir $(2,4)$. Biz de ADA uyguladığımız tüm ünitelerde; oksijen kaynağı, kalp atım hızı, tansiyon arteriyel ve oksijen satürasyon ölçümü yapabilen monitör, aspiratör, laringoskop, acil ressüsitasyon malzemesi içeren acil çantası veya dolabı, defibrilatör bulundurduk. Mevcut klavuzlarda ekibin deneyimli olması gerekliliği, acil durumlarda ortam koşullarından kaynaklanan güçlüklerden de söz edilmiştir. Bu sebeple bizim ADA ekibimizde bir anestezi uzmanı, bir kıdemli anestezi asistanı ve bir anestezi teknisyeninden oluşmaktadır.

Cerrahi dışı anestezi uygulamalarında güvenliğin ön koşulu; hastanın tıbbi durumunu önceden değerlendirmek, yapılacak girişimin özelliklerini bilmek ve ekipman gereksinimini ameliyathane içindeki anestezi yaklaşımı ile eşdeğer görmektir. Ameliyathanedeki ile aynı kalitede klinik bakım ve izlem koşullarını sağlamak için; bir yandan anestezi ve izlem cihazlarına, diğer yandan da morbiditesi daha az ve hızlı derlenmeye olanak sağlayan farmakolojik ajanlara yönelim vardır (1-4).

Farmakolojik ajanlarla elde edilebilecek sedasyon bilinçli sedasyon veya derin sedasyon olmak üzere farklı iki düzeyde olabilir. Sedasyon seçimi, girişimin süresine, ağrılı olup olmadığına, pozisyona, girişimin yan etkisine, hastanın anksiyetesi ve stresine, kooperasyon kurulamamasına, hastanın geçmiş deneyimlerine, allerji öyküsüne, istenmeyen ilaç reaksiyonlarına, aspirasyon riskine göre yapılmalıdır $(2,5)$. Anestezik ilaçların seçimi; hastanın durumuna, kullanılacak olan ilacın hemodinami üzerine olan etkilerinin iyi bilinmesine göre değişmektedir $(2,5)$. Hastalarda tüm koruyucu reflekslerin sürdüğü, hastanın kendi hava yolu açıklığını koruyabildiği, fiziksel uyarı ve sözel komutlar ile istenilen yanıtı verdiği bilinçli sedasyon yöntemi ADA uygulamalarında sık uygulanan bir yöntemdir (5). Biz de işlemin ağrılı olması, pozisyon, uygulama alanı ve olgunun özelliklerine göre olguya bilinçli veya derin sedasyon yöntemlerini uyguladık.

En yüksek oradan endoskopik girişimlerde ADA uyguladık.1890 olguda propofol+alfentanil, 499 olguda propofol+fentanil, 115 olguda ketofol tercih edildi. Roseveare ve ark. yaptıkları çalışmada kolonoskopi de propofol ve alfentanil kullanmış ve bu kombinasyonu benzodiazepinlerden daha kısa etkili ve efektif bulmuşlardır (6). Kulling ve ark. kolonoskopide propofol-alfentanil kombinasyonu ile midazolam ve meperidini karşılaştırdıkları çalışmada, hem uyanma zamanını kısa bulmuş, hem de hasta memnuniyetinin fazla olduğunu rapor etmişlerdir (7). Kolonoskopilerde midazolam ile birlikte alfentanil ve fentanil kullanımını karşılaştıran çalışmada, uyanma zamanı benzer bulunmuş ancak alfentanilin daha iyi operatif şartlar sağladığı bildirilmiştir (8). Propofol ile kombine opioidlerin analjezi ve amnezi sağladığı, bulantı, kusma ve solunum depresyonu gibi yan etki insidansını azalttığını bildiren çalışmalar mevcuttur (6-8). Ketofolunde analjezik özellikleri belirgindir ve hemodinamik açıdan stabilize edici bir etkisi vardır. Kullanımı iyi bir konfor sağlamanın ötesinde opioidlerden kaçınılmasını sağlar (9).

İnfantlar, çocuklar ve bazı gelişimsel geriliği olan ergenler MRG sırasında yeterli hareketsizliği sağlayabilmek için sıklıkla sedasyona ihtiyaç duyarlar 10.873 olguda MRG ve BT'de ADA uygulanmıştır. 725 olguya propofol, 83 olguya deksmetedomidin, 65 olguya midozolam+ketamin uygulandı. Propofolün, tiopental, midozalam ve kloralhidrat gibi ajanlarla karşılaştırıldığı çalışmalarda propofolle daha hızlı sedasyon 
başlangı ICı, çabuk derlenme ve etkin sedasyon elde edilmiş. Solunumsal ve kardiyak yan etkiler kabul edilebilir sınırlarda bulunmuştur $(11,12)$. Propofol ve deksmetedomidini karşılaştıran çalışmalarda da, propofolle daha hızlı etki başlangıcı ve derlenme görülmekle birlikte, anestezi kalitesi iki ajanda benzer bulunmuştur. Deksmetedomidinin daha az kardiak ve solunumsal depresyon yaptığının görülmesi ile propofole MRG uygulanan çocukların anestezisinde alternatif olabileceği düşünülmüştür $(13,14)$. Malviya ve ark. çalışmasında çocuklarda tanısal işlemler için yapılan sedasyonlarda komplikasyon oranının \%20.1 olduğu ve bunların büyük çoğunluğunun (\%5.5) solunum komplikasyonlarının oluşturduğu rapor edilmektedir (15). İnönü Üniversitesinde MRG sebebiyle ADA uygulanan 1458 pediatrik olguda Öztürk ve arkadaşlarının yaptığı çalışmada 3 olgunun eksitus olduğu, 168 olguda minör komplikasyon geliştiği söylenmektedir (3). Bizim olgularımızında da \%2,9 oranında solunum komplikasyonu görülmüştür.

EKT uygulaması 36 olguya 234 seans uygulanmıştır. 234 seansın 90'ında etomidate+süksinilkolin, $144^{\prime}$ ünde propofol+süksinilkolin uygulandı. Etomidate nöbet eşiğini düşürerek daha uzun nöbet süresi sağlamaktadır. Yüksek elektiriksel uyarıya karşın etkin nöbet elde edilemeyen olgularda propofole tercih edilir. Propofol kısa nöbet süresine rağmen, hızlı derlenme sağlaması sebebiyle ilk tercihtir (16).

Girişimsel nöroradyoloji komplike bir alandır ve doğası gereği önemli düzeyde morbidite riski taşımaktadır. Hastaların genellikle birkaç saat hareketsiz kalmasına, bazı kritik aşamalarda nörolojik değerlendirmeye ve kan basıncının yükseltilmesine ya da düşürülmesine gereksinim duyulmaktadır. Girişimsel nöroradyoloji ünitesi, anestezi yönünden, bir beyin cerra-

\section{KAYNAKLAR}

1. Leyla Iyilikçi, Şükran Çakmak, Ece Ögdül, Başak Candüz, Figen Boyacı, Emine Özdemir, Emine Kocaayan. Ameliyathane Dışı Anestezi Uygulamalarında Deneyimlerimiz. Türk Anest Rean Der Dergisi 2006;34(3):169-176.

2. Türk Anesteziyoloji ve Reanimasyon Derneği (TARD) Anestezi UygulamaKlavuzları.Ameliyathane Dışı Anestezi Uygulamaları 2005; Kasım.

3. Öztürk E, Yücel A, Begeç Z, Erdil FA, Demir K, Ersoy MÖ. Manyetik Rezonans Görüntüleme Ünitesindeki Pediyatrik Olgularda Anestezi Deneyimlerimiz. Inönü Üniversitesi Tıp Fakültesi Dergisi 2008;15(4):239-43. hisi ameliyathanesi ile benzer donanıma sahip olmalıdır (17). Genellikle A-V malformasyon embolizasyonundan önce besleyici arterde kan akımını azaltmak için kontrollü hipotansiyon, herhangi bir serebral iskemi durumunda ise başlangıç değerinin \%30-40 kadar yükseğinde kontrollü hipertansiyon gerekli olur (17). Bizde anjiografi ünitesinde anevrizma embolizasyonuna genel anestezi uyguladık. Bu işlemler esnasında invaziv tansiyon arteriyel takibi yaptık. Hastanemizde anjiografi ünitesi ameliyathanenin hemen yanında yer almaktadır. Anjio sonrası hastalar 24 saat beyin cerrahisi yoğun bakımında takip edilmektedir.

RT uygulanan çocuklarda işlem başarısı için tam hareketsizlik gerekmektedir. Bu sebeple de tekrarlayan anestezi uygulamalarına ihtiyaç duyulmaktadır. 15 olguda 106 seans RT uygulamasında propofol ile ADA uyguladık. Yapılan çalışmalarda kısa derlenme süresi ile propofolün uygun bir ajan olduğunu göstermektedir (18). Ayrıca RT esnasında hastanın oda da yalnız kalması işleme ait en büyük riski oluşturmaktadır. Propofol uygulanmış 3884 RT hastasında komplikasyon oranı \%1.3 bulunmuştur (19). Biz de RT uygulamalarımızda komplikasyonla karşılaşmadık.

ADA uygulamalarında morbidite ve mortalite oranları konusunda literatürde geniş çaplı çalışma mevcut değildir. 9 Eylül Üniversitesinde ADA uygulanan 1622 olguda yapılan çalışmada İyilikçi ve arkadaşları 6 majör, 40 minör komplikasyonla karşılaşmşlardır (1). Bizde \%6,2 oranında komplikasyonla karşılaştık.

Sonuç olarak; ADA uygulamalarında yapılacak uygulamanın ve görüntülemenin etkilerini önceden saptayarak, yeterli teknik donanım ve monitörizasyonun olmasına dikkat ederek, sedasyon amacıyla kısa etkili ve çabuk derlenme sağlayacak ajanları seçerek, hayati komplikasyonlar önlenebilir.
4. Guidelines of the American Society of Anesthesiologist: Directory of members, American Society of Anesthesiologist, 1997:394-404.

5. Korkmaz T, Ateş Y. Ameliyathane dışı anestezi uygulamaları. Editörler: Özatamer O, Alkış N, Batıislam Y, Küçük. Anestezide Güncel Konular. Ankara: Nobel Tıp Kitapevleri; 2002:371-91.

6. Roseveare C, Seavell C, Patel P, Criswell J, Shepherd $H$. Patient-controlled sedation with propofol and alfentanil during colonoscopy: a pilot study. Endoscopy 1998;30(5):482-3.

7. Külling D, Fantin AC, Biro P, Bauerfeind P, Fried M. Safer colonoscopy with patient-controlled analgesia and sedation with propofol and alfentanil. Gastrointest Endosc 2001;54(1):1-7. 
8. Holloway AM, Logan DA. Pain relief for out patient colonoscopy: a comparison of alfentanil with fentanyl. Anaesth Intensive Care 1990;18(2):210-3.

9. Mustafaeva MN, Mizikov VM, Kochneva ZV. Drug sedation during digestive tract endoscopy: current trends. Anesteziol Reanimatol 2009;(4):32-8.

10. Gooden CK. Anesthesia for magnetic resonance imaging. Current Opinion in Anesthesiology August 2004;17:339-42.

11. Priti GD, Murray D, Cox T, McAllister J, Snider R. Sedation and anesthesia protocols used for magnetic resonance imaging studies in infants: provider and pharmacologic considerations. Anesthesia and Analgesia 2006 Oct;103(4):863-8.

12. Pershad J, Wan J, Anghlescu DL. Comparison of propofol with pentobarbital/midazolam/fentanyl sedation for magnetic resonance imaging of brain in children. Pediatrics 2007 sep; 120(3):629-36.

13. Koroğlu A, Teksan H, Sağır O. A comparison of the sedative, hemodynamic, and respiratory effects of dexmedetomidine and propofol in children undergoing magnetic resonance imaging. Anesthesia and Analgesia 2006;103:63-67.
14. Dave j, Vaghela S. A comparison of the sedative, hemodynamic and respiratory effects of demedetomidine and propofol in children undergoing magnetic resonance imaging. Saudi journal of Anaesthesia 2011 jul-sep;5(3):295-299.

15. Malviya S, Voepel-Lewis T, Tait AR. Adverse events and risk factors associated with the sedation of children by nonanesthesiologist. Anesth Analg 1997;85:1207-13.

16. Moacyr A Rosa, Marina O Rosa, lara M T Belegarde, Celso $R$ Bueno, Felipe Fregni. Recovery after ECT: comparison of propofol, etomidate and thiopental. Rev Bras Psiquiatr. 2008;30(2):149-51.

17. Aypar Ü, Pamuk AG. Girişimsel radyoloji ve anestezik yaklaşım. Anestezi Dergisi 2007;15(3):149-60.

18. McFadyen JG, Pelly N, Orr RJ. Sedation and anesthesia for the pediatric patient undergoing radiation therapy. Curr Opin Anaesthesiol 2011 Aug;24(4):433-8.

19. Anghelescu DL, Burgoyne LL, Liu W, Hankins GM, Cheng $C$, Beckham PA, Shearer J, Norris AL, Kun LE, Bikhazi GB. Safe anesthesia for radiotherapy in pediatric oncology: St. Jude Children's Research Hospital Experience, 2004-2006. Int J Radiat Oncol Biol Phys 2008 Jun 1;71(2):491-7. 